\title{
Chromosomal Abnormalities in Reimplantation Development
}

\author{
Anver Kuliev *, Zev Zlatopolsky and Svetlana Rechitsky
}

Reproductive Genetic Innovations, Chicago, IL, USA

*Corresponding author: Anver Kuliev, Reproductive Genetic Innovations, Chicago, IL, USA, Tel: +1 847-400-1515; E-mail: anverkuloiev@hotmail.com

Received date: Dec 11, 2015; Accepted date: Feb 09, 2016; Published date: Feb 12, 2016

Copyright: () 2016 Kuliev A, et al. This is an open-access article distributed under the terms of the Creative Commons Attribution License, which permits unrestricted use, distribution, and reproduction in any medium, provided the original author and source are credited.

\begin{abstract}
Direct testing of the outcome of human female meiosis demonstrated that up over a half of oocytes from IVF patients of advanced reproductive age are aneuploid, originating comparably from meiosis I and meiosis II errors, with potential probability of aneuploidy rescue in an almost half of oocytes with sequential first and second meiotic errors. One fifth of abnormalities originating from meiosis I and II are of complex nature, with nonrandom distribution of chrmomatid/chromosome (10:1 ratio), and missing/extra chromotid (chromosome) errors (2:1 ratio). The data also demonstrate the relationship between embryo viability and meiotic origin of chromosomal errors, affecting their clinical impact on preimplantation and post-implantation development.
\end{abstract}

Keywords: Aneuploidy testing of oocytes and embryos; Aneuploidy rescue in female meiosis; Chromosome and chromatid nondisjunction; Embryo viability depending on meiotic origin; Meiosis I and meiosis II errors

\section{Introduction}

According to DNA polymorphism studies performed in families with aneuploid spontaneous abortions and live-born babies, chromosomal abnormalities originate predominantly from female meiosis I, probably due to reduction of meiotic recombination rate with advanced reproductive age [1-3]. It was also suggested that meiosis II errors may, on the opposite, be a result of the increased meiotic recombination rate [4]. However, this was based not on the direct testing of meiosis errors, but limited to the testing of those products of conception that are compatible with implantation, resulting in recognized pregnancies, which either survived to term or aborted spontaneously. Because of the limitations of the testing methodologies of meiotic chromosomes in the past, chromosomal anomalies in oocytes were considered mainly of chromosomal type, involving the errors of whole bivalents, while, as will be described below, it appeared that only a minority of errors are of chromosomal type, and, instead, the primary errors are represented by chromatid mal-segregation [5-9]. This was extensively demonstrated by the experience of preimplantation aneuploidy testing, using the first and second polar body sampling with follow up analysis of the resulting embryos [10-13], which will be reviewed in this paper.

\section{Prevalence of Aneuploidies in Preimplantation Development Based on Direct Testing of Female Meiosis Outcome}

Approximately, half of human oocytes obtained from women 39 and older are with chromosomal anomalies, based on the testing for five common aneuploidies, and $70 \%$ or higher, based on testing for all 24 chromosomes [10-14] [Table 1], with higher aneuploidy rates with increasing maternal age. Despite the previous reports, mentioned, that the majority of these abnormalities are of the meiosis I origin, it appeared that there is no significant difference between the prevalence of the errors originating from meiosis I and II (31\% and $34 \%$, respectively) [Table 2]. So the predominance of aneuploideies of the female meiosis I origin in the previous studies, based on testing of the live-born babies and spontaneous abortions, is probably due to the incompatibility of the majority of meiosis II errors with implantation. In fact, as can be seen from Table 1, the majority of aneuploidies are lost before or during implantation, resulting in only one in ten embryos with aneuploidies surviving implantation, in contract to seven to ten in preimplantation development.

\begin{tabular}{|l|l|}
\hline \multicolumn{2}{|l|}{ Development } \\
\hline Preimplantation & $70 \%$ \\
\hline Posimplantation & $10 \%$ \\
\hline At birth & $0.50 \%$ \\
\hline
\end{tabular}

Table 1: Aneuploidy prevalence in pre- and post-implantation.

\begin{tabular}{|l|l|l|l|l|}
\hline \multicolumn{4}{|l|}{ Meiosis I } & \multicolumn{2}{l|}{ Meiosis II } \\
\hline FISH Data & No. & $\%$ & No. & $\%$ \\
\hline Normal & 13097 & 69 & 13635 & 66 \\
\hline Abnormal & 1514 & 26 & 2721 & 39 \\
\hline Disomy & 3136 & 53 & 2875 & 41 \\
\hline Nullisomy & 1271 & 21 & 1342 & 19 \\
\hline Complex & 5921 & 31 & 6938 & 34 \\
\hline Total abnormal & 19018 & 100 & $\mathbf{2 0 5 7 3}$ & 100 \\
\hline Total & &
\end{tabular}

Table 2: Types of Meiosis I and Meiosis II errors (Based on 10-13).

So, perhaps the meiosis II errors loss represents proportionally the larger proportion of the lost aneuploidies. Of special interest is also the fact that almost one third of chromosomal abnormalities are due to 
sequential meiosis I and meiosis II errors, suggesting that some of the meiosis II errors may be resulting from the preceding meiosis I errors, although it may also be determined by generalized disturbances in female meiosis due to advance reproductive age. The other unexpected phenomenon, discovered by testing of the direct outcome of female meiosis, is the 10:1 ratio of chromatid/chromosome errors, which may suggest that despite the expected disjunction or non-disjunction of the whole chromosomal bivalents in meiosis I, each of the sestrid chromatids of the corresponding bivalents are distributed randomly and independently, and any lack or addition of a chromatid may lead respectively to a trisomy or nullisomy. In addition, a phenomenon of the excess of nullisomy over trisomy (2:1 ratio) was observed in meiosis I [Table 2], which will lead as a result to a trisomy, probably due to a possible meiosis I mechanism that prevents an extra chromosome material extrusion during oocyte maturation process, avoiding monosomy status of the resulting embryo. This was first observed with the application of FISH technique and then confirmed by utilization of microarray technology for 24-chromosomes aneuploidy testing [12-14]. However, the above ratio was not consistent with the monosomy /trisomy ratio observed in the cleavage preimplantation embryos, demonstrating a predominance of monosomies over trisomies $[12,13,15,16]$. It is of interest that no maternal age dependence was revealed for the majority of monosomies observed in the cleaving embryos [17], suggesting that the majority of monosomies detected in embryos at this stage may derive from mitotic errors, that may disappear at the blastocyst stage and was reported not to be detected after reanalysis with different probes $[18,19]$. So some of the monosomies are either eliminated before implantation, or have no biological significance, reflecting the poor viability of the monosomic embryos and their degenerative changes. However, the majority of prezygotically derived monosomies, as well as some of the post-zygotic ones are still survive to the blastocyst stage, and, therefore, lead to implantation failure or fetal loss. One of the contributing factor to this inconsistency is also a high prevalence of mosaicism at the cleavage stage, the overall prevalence of which, as mentioned, does not show any relationship with maternal age [15-17], suggesting that a significant proportion of mosaicism may have no clinical relevance or transitional without affecting the embryo viability. But still some portion of mosaicism is related to maternal age [17], which clearly is derived from aneuploid zygotes.

\section{Aneuploidy Rescue in Female Meiosis, Their Impact on Embryo Viability and its Relationship to Meiotic Origin}

Approximately one fifth of abnormalities originating from meiosis I and II ( $21.5 \%$ and $19.3 \%$, respectively; Table 2$)$ were of complex origin, represented by different types of errors, errors involving more than one chromosome, or errors in both meiosis I and II of same or different chromosome [10-13]. Of the overall oocytes with complex errors, $63 \%$ involved simultaneously the errors of different chromosomes, and 37\% the same chromosome (s) errors. Of the oocytes with both meiosis errors, $45 \%$ zygotes appeared to be balanced following these sequential errors, representing a phenomenon of aneuploidy rescue [Table 3]. The fate of the embryos resulting from such balanced oocytes is not understood, but may lead to the formation of mosaic embryos, or to those with uniparental disomy and imprinting disorders. Although the aneuploidy rate was higher with introduction of 24-chromosome aneuploidy testing, which increased from 50 to $71 \%$, it has also changed the structure of aneuploidy types, with particular increase of the complex abnormalities, This is in agreement with the observation in animal studies, showing that the meiotic error of one chromosome may affect the segregation of other chromosomes [20]. As mentioned above, the majority of meiosis II errors are not compatible with implantation, explaining the lack of these abnormalities in spontaneous abortions and live-born children with chromosomal trisomies. This was confirmed also by our data on chromosome specific origin of errors (Table 4), demonstrating that chromosome 16 and 22 errors originate more frequently in meiosis II $(44.4 \%$ and 41.5 $\%$ meiosis II errors vs. $32.0 \%$ and $34.3 \%$ meiosis I, respectively), in contrast to chromosome 13,18 , and 21 errors more frequently from meiosis I (40.1, 48.3 and $41.4 \%$ in meiosis I vs. $36.3,34.6$ and $36.7 \%$ in meiosis II, respectively). This is also in contrast to the data obtained on the material of spontaneous abortions and live-born children, indicating to poor viability of embryos resulting from the oocytes with the chromosome 16 and 22 errors of the second meiotic division origin, which may be incompatible with implantation and postimplantation development. Although there is no understanding of biological differences of aneuploidies depending on the meiotic origin, it may well be due to a loss of heterozygosity or higher homozygosity of the embryos originating from meiosis II errors. The data provides the first evidence for possible viability differences dependent on the meiotic origin of the error.

\begin{tabular}{|l|l|l|}
\hline Chromosome 13 only & 155 & $5.3 \%$ \\
\hline Chromosome 16 only & 248 & $8.5 \%$ \\
\hline Chromosome 18 only & 127 & $4.4 \%$ \\
\hline Chromosome 21 only & 418 & $14.3 \%$ \\
\hline Chromosome 22 only & 436 & $14.9 \%$ \\
\hline Different Chromosomes ${ }^{*}$ & 1414 & $48.4 \%$ \\
\hline Abnormal for $>1$ Same Chromosomes & 123 & $4.2 \%$ \\
\hline Total & 2921 & $100 \%$ \\
\hline Total Balanced & 1314 & $45.0 \%$ \\
\hline $\begin{array}{l}\text { *The same chromosome can be involved in both meiosis I and II when } 2 \text { or } \\
\text { more chromosomes are involved. }\end{array}$ & \multicolumn{2}{|l}{} \\
\hline
\end{tabular}

Table 3: Oocytes with both Meiosis I and Meiosis II errors (12-13).

\begin{tabular}{|l|l|l|l|l|}
\hline Chromosome & $\begin{array}{l}\text { Total Abnormal } \\
(\%)\end{array}$ & $\begin{array}{l}\text { Meiosis I } \\
\text { Origin }\end{array}$ & $\begin{array}{l}\text { Meiosis II } \\
\text { Origin }\end{array}$ & $\begin{array}{l}\text { Meiosis I and Meiosis II } \\
\text { Origin }\end{array}$ \\
\hline 13 & $1086(12.6)$ & $436(40.1)^{\mathrm{a}}$ & $394(36.3)^{\mathrm{a}}$ & $256(23.6 \%)$ \\
\hline 16 & $1531(17.8)$ & $\begin{array}{l}490(32.0) \\
\mathrm{P}=0.000\end{array}$ & $\begin{array}{l}679(44.4) \\
\mathrm{P}=0.000\end{array}$ & $\begin{array}{l}362(23.6) \\
\text { NS }\end{array}$ \\
\hline
\end{tabular}


Citation: Anver K, Zev Z, Svetlana R (2016) Chromosomal Abnormalities in Reimplantation Development. Human Genet Embryol 6: 134. doi: 10.4172/2161-0436.1000134

Page 3 of 3

\begin{tabular}{|l|l|l|l|l|}
\hline 18 & $1098(12.8)$ & $\begin{array}{l}530(48.3) \\
\mathrm{P}=0.000\end{array}$ & $\begin{array}{l}380(34.6) \\
\text { NS }\end{array}$ & $\begin{array}{l}188(17.1) \\
\mathrm{P}=0.000\end{array}$ \\
\hline 21 & $2151(25.0)$ & $\begin{array}{l}891(41.4) \\
\text { NS }\end{array}$ & $\begin{array}{l}790(36.7) \\
\text { NS }\end{array}$ & $\begin{array}{l}470(21.9) \\
\text { NS }\end{array}$ \\
\hline 22 & $2736(31.8)$ & $939(34.3)$ & $1135(41.5)$ & $662(24.2)$ \\
& & $P=0.001$ & P $=0.003$ & \\
\hline *Chi-square analysis, comparison to a, statistically significant $P$ value $<0.05$ & & \\
\hline
\end{tabular}

Table 4: Origin of chromosome 13, 16, 18, 21 and 22 aneuploidies (10-13).

\section{References}

1. Sherman SL, Petersen MB, Freeman SB, Hersey J, Pettay D, et al. (1994) Nondisjunction of chromosome 21 in maternal meiosis I: evidence for a maternal age-dependent mechanism involving reduced recombination. Hum Mol Genet 3: 1529-1535.

2. Hassold T, Merril M, Adkins K, Freemen S, Sherman S (1995) Recombination and maternal age-dependent nondisjunction: molecular studies of trisomy 16. Am J Hum Genet 57, 867-874.

3. Peterson MB, Mikkelsen M (2000) Nondisjunction in trisomy 21: Origin and mechanisms. Cytogenet Cell Genet 91: 199-203.

4. Lamb NE, Freeman SB, Savage-Austin A, Pettay D, Taft L (1996) Susceptible chiasmate configurations of chromosome 21 predispose to nondisjunction in both maternal meiosis I, and meiosis II. Nat Genet 14: 400-405.

5. Dyban A, Fredine M, Severova E, Cieslac J, Wolf G, et al. (1996) Detection of aneuploidy in human oocytes and corresponding first polar bodies using FISH. 7th International Conference on Early Prenatal Diagnosis. Jerusalem, Israel, 1994; May 22-27.

6. Verlinsky Y, Cieslak J, Freidine M, Ivakhnenko V, Wolf G, et al. (1995) Pregnancies following pre-conception diagnosis of common aneuploidies by fluorescent in-situ hybridization. Hum. Reprod 10:1923-1927.

7. Munné S, Daily T, Sultan KM, Grifo J, Cohen J (1995) The use of first polar bodies for preimplantation diagnosis of aneuploidy. Hum. Reprod 10: 1014-1120.

8. Dyban A, Freidine M, Severova E, Cieslak J, Ivakhnenko V, et al. (1996) Detection of aneuploidy in human oocytes and corresponding first polar bodies by FISH. J Assist Reprod Genet 13: 72-77.

9. Verlinsky Y, Cieslak J, Ivakhnenko V (1996) Birth of healthy children after preimplantation diagnosis of common aneuploidies by polar body FISH analysis. Fertil Steril 66: 126-129.

10. Kuliev A, Zlatopolsky Z, Kirillova I, Spivakova J, Cieslak-Janzen G (2011) Meiosis errors in over 20,000 oocytes studied in the practice of preimplantation aneuploidy testing. Reproductive BioMedicine 22: 2-8.
11. Kuliev A (2012) Practical Preimplantation Genetic Diagnosis. Springer, London, NY.

12. Kuliev A, Cieslak J, Verlinsky Y (2005) Frequency and distribution of chromosomal abnormalities in human oocytes. Cytogenet Genome Res 111: 193-198.

13. Kuliev A, Rechitsky S, Verlinsky O (2014) Atlas of Preimplantation Genetic Diagnosis. 3rd Edition. CRS Press, Taylor and Francis, London.

14. Gabriel AS, Thornhill AR, Ottolini CS (2011) Array comparative genomic hybridization on first polar bodies suggests that non-disjunction is not the predominant mechanism leading to aneuploidy in humans. J Med Genet 48: 433-437.

15. Munné S, Sandalinas M, Escudero T, Marquuez C, Cohen J (2002) Chromosome mosaicism in cleavage stage human embryos: evidence of a maternal age effect. Reproductive BioMedicine Online 4: 223-232.

16. Munne S (2007) Chromosomal Status of Human Embryo 2007 In: Human Preimplantation Embryo Selection. Edited by Elder K, Cohen J. Informa Healthcare, London UK; pp 209-234.

17. Munne S, Sandalinas M, Escudero T (2002) Some Mosaic Types Increase with Maternal Age. Reproductive BioMedicine 4: 223-232.

18. Colls P, Escudero T, Cekleniak N, Sadowy S, Cohen J (2009) Increased efficiency of preimplantation genetic diagnosis for aneuploidy by testing 12 chromosomes. Reprod BioMed 19: 532-538.

19. Uher P, Baborova P, Kralickova M, Zech MH, Verlinsky Y, et al. (2009) Non-informative results and monosomies in PGD: the importance of a third round of re-hybridization. Reproductive BioMedicine 18: 530-546.

20. Hunt P, LeMaraire R, Embury P, Sheean L, Mroz K (1995) Analysis of chromosome behaviour in intact mammalian oocytes: monitoring the segregation of a univalent chromosome during female meiosis. Hum Mol Genet 4: 2007-2012. 